\title{
Voltaire, Voltaire éditeur. Euvres de 1769-1770 (I)
}

\section{Franco Piva}

\section{(2) OpenEdition}

\section{Journals}

\section{Edizione digitale}

URL: https://journals.openedition.org/studifrancesi/26346

DOI: 10.4000/studifrancesi.26346

ISSN: 2421-5856

\section{Editore}

Rosenberg \& Sellier

\section{Edizione cartacea}

Data di pubblicazione: 1 avril 2007

Paginazione: 181

ISSN: 0039-2944

\section{Notizia bibliografica digitale}

Franco Piva, «Voltaire, Voltaire éditeur. Euvres de 1769-1770 (I)», Studi Francesi [Online], 151 (LI | I) | 2007, online dal 30 novembre 2015, consultato il 23 novembre 2021. URL: http://

journals.openedition.org/studifrancesi/26346 ; DOI: https://doi.org/10.4000/studifrancesi.26346

Questo documento è stato generato automaticamente il 23 novembre 2021.

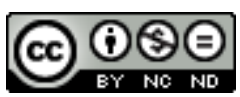

Studi Francesi è distribuita con Licenza Creative Commons Attribuzione - Non commerciale - Non opere derivate 4.0 Internazionale. 


\section{Voltaire, Voltaire éditeur. Cuvres de 1769-1770 (I)}

\section{Franco Piva}

\section{NOTIZIA}

VOLTAIRE, Voltaire éditeur. CEuvres de 1769-1770 (I), Oxford, Voltaire Foundation, 2005 («Les CEuvres complètes de Voltaire», 71A), pp. XXIII + 335.

Questo volume, come il 71B, che abbiamo presentato nel numero 149 di «Studi Francesi», è consacrato ad un aspetto dell'attività letteraria di Voltaire al quale il Patriarca di Ferney ha prestato particolare attenzione nel biennio 1769-1770 e che si è tradotta nella ripresentazione al pubblico francese di cinque testi (due, il Discours de l'empereur Julien contre les chrétiens e la Sophonisbe, tragédie de Mairet, réparée à neuf nel volume 71B e tre, Le «Cymbalunm mundi» en français, Les Souvenirs de Madame de Caylus ed il Journal de la Cour de Louis XIV depuis 1694 jusqu'à 1715 in questo). Letti di seguito i titoli riproposti da Voltaire paiono, ed in buona parte sono, alquanto disparates, e sembra a prima vista difficile individuare la logica che ha sotteso al recupero di questi testi di natura, origine ed epoca tra loro diverse. Se si analizzano da vicino, come consentono di fare le edizioni accuratamente preparate da Nicholas Kronk per il cymbalum mundi e per il Journal de la cour de Louis XIV e da Janet Godden e Virgil Topazio per i Souvenirs de Madame de Caylus, ci si rende tuttavia conto che queste operazioni rispondono ad alcune delle preoccupazioni più assidue di Voltaire, in particolare quelle alle quali egli era soprattutto sensibile in quegli anni per ragioni contingenti. Per quanto riguarda il Discours de l'empereur Julien ed il Cymbalum mundi la decisione di Voltaire di riproporli con un'annotazione e, soprattutto, con un'Introduzione che delle due opere proponeva una lettura almeno in parte nuova, e più morbida rispetto a quelle precedenti, nasceva dal desiderio, o dalla necessità, per il philosophe di contrecarrer in qualche misura gli effetti, ed i rischi, che poteva comportare per il pubblico dell'epoca, e più specificatamente per la battaglia che Voltaire stava conducendo da tempo a favore di una religione moderata e trasparente, il crudo materialismo propugnato dal système de 
la nature di d'Holbach, uscito proprio nel 1770 , riducendo il significato materialista, se non anticristiano, di un'opera, come il Discours de l'empereur Julien la cui edizione precedente proprio su questo aspetto aveva insistito, oppure nel far notare come il valore materialista dell'altra opera, il Cymbalum mundi, trovasse il suo fondamento in una tradizione assolutamente infondata, l'opera attribuita a Des Périers non essendo, di fatto, che una «froide imitation de Rabelais».

Per quanto riguarda i Souvenirs de Madame de Caylus e il Journal del marchese Dangeau, si trattava di rendere pubbliche due testimonianze, una assai poco nota, l'altra di per sé troppo dispersiva, che per assumere significato e leggibilità doveva essere presentata solo per frammenti che Voltaire ha raccolto significativamente sotto il titolo di Journal de la cour de Louis XIV, trasformandola così in un'opera imperniata sulla figura di quel Re Sole, del quale non solo il marchese Dangeau era stato un fedele servitore, ma che aveva anche segnato un'epoca indubbiamente felice della storia e soprattutto della cultura francese, dalla quale, nonostante le critiche formulate a più riprese, Voltaire rimase sempre affascinato. Vista da questo punto di vista, assume il suo significato più preciso anche la riscrittura della Sophonisbe di Mairet. Per Voltaire si trattava di riproporre al pubblico del 1770 «la mère de toutes les tragédies françaises» in uno stile che fosse consono al gusto ed alle esigenze estetiche dell'epoca, in uno stile che fosse cioè depurato da quelle incertezze e da quei difetti che caratterizzavano la lingua francese al tempo di Mairet. Si trattava cioè di «ranimer», di «ressusciter», di riportare nell'alveo della grande tradizione letteraria francese un'opera altrimenti destinata a perdesi nell'oblio delle cose imperfette.

L'attività editoriale di Voltaire di questi anni deve quindi essere vista e valutata alla luce del modo in cui l'intese lui: le esigenze che lo animarono non erano filologiche nel senso in cui noi intendiamo ora il termine, ma storiche e funzionali alle preoccupazioni che lo animavano in quel momento. Hanno tuttavia fatto bene i curatori del volume a riprodurre, accanto alle introduzioni ed alle note di Voltaire, anche i testi che egli intese riproporre all'attenzione dei suoi lettori, in quanto il confronto (un confronto che nella maggior parte dei casi è possibile effettuare solo dopo questa edizione) consente allo studioso di valutare attentamente, e con piena cognizione di causa, non solo l'atteggiamento che Voltaire assunse di fronte a questi testi ma anche la portata ed il significato dell'infléchissement che la sua «lettura» ha fatto loro subire. 